\title{
THE ROLE OF OLFACTORY AND GUSTATORY STIMULI IN THE FEEDING BEHAVIOUR OF GRASS GRUBS
}

\author{
O. R. W. SutherLand \\ Entomology Division, DSIR, Nelson
}

\begin{abstract}
Summary
By recording the paths followed by Costelytra zealandica larvae in vermiculite-filled glass chambers, a strong olfactory attraction to fresh ryegrass root has been demonstrated. Volatile substances in a chloroform extract of similar root material were also attractive to the grubs. Several water-soluble nutrient chemicals, notably sucrose, maltose, aspartic acid, glutamic acid and ascorbic acid (vitamin C) have been shown to be strong phagostimulants for this insect. The view that $C$. zealandica larvae ingest soil and nutrient matter indiscriminately is not supported.
\end{abstract}

\section{INTRODUCTION}

THE DAMAgE caused to pasture plants by the polyphagous grass grubs (Costelytra zealandica) results entirely from their feeding habits. It is, therefore, surprising that there has to date been scant study of the feeding behaviour of these insects. Perhaps the desire to kill grubs in a particular area has overshadowed the need to determine why they are present in that area in the first place. The fundamental importance of detailed studies of the feeding behaviour of pest insects has been stressed (Painter, 1951) and has relevance both in attempts at obtaining resistant species of pasture plants and in efforts to control pest insects by artificially manipulating or disrupting their behaviour patterns.

The importance of the role played by chemical stimuli in the feeding behaviour of phytophagous insects has often been stressed (see, for example, Schoonhoven, 1968; Dethier, 1970). Those substances which attract phytophagous insects to a potential food source are termed "attractants" (Dethier et al., 1960). Because they function as olfactory stimulants, attractants must be volatile substances. Once the insect has located the plant, an "arrestant" may halt the searching behaviour, whereupon a "biting stimulant" can then cause a test bite to be taken. Sustained feeding depends, however, upon the presence of, and the balance between, feeding stimulants (phagostimulants) and feeding deterrents. Chemicals in the latter two categories are usually in solution and are perceived by gustatory receptors on the larval antennae and mouth parts.

The present paper reports the olfactory response of larvae to the odours of fresh plant root material, and the gustatory response to various nutrient chemicals many of which are present in solution in that root material.

The LaRvae

MATERIALS AND METHODS

Third instar C. zealandica larvae were collected from the field and were starved at room temperature for $24 \mathrm{~h}$. Active, vigorous grubs were then selected for the bioassays. 


\section{BIOASSAYS}

\section{(1) Olfactory Response}

Details of this bioassay are given elsewhere (Sutherland, 1972). Square, glass-sided chambers, $15 \times 15 \times 0.6 \mathrm{~cm}$ with a removable lid were filled with damp vermiculite. The test odour source (root, or extract-treated filter paper) was then enclosed in a $15 \times 1 \mathrm{~cm}$ envelope of fine mesh stainless steel gauze, and appropriate blanks were enclosed similarly. A gauze containing the test material was placed on one side of the chamber and a blank gauze was laid parallel to this $5 \mathrm{~cm}$ away, leaving a test arena of $15 \times 5 \mathrm{~cm}$. The chambers were then closed for $3 \mathrm{~h}$ to allow the odours to diffuse into the arena, after which they were opened briefly and three larvae were placed vertically down the centre line of the test arena. The chambers were closed and transferred to a dark room illuminated by a central dim red light. They were laid flat on a table beneath the light and were observed continuously for $2.5 \mathrm{~h}$. The paths followed by individual larvae were recorded on graph paper and every 15 minutes the number of grubs present at either the control gauze or that containing the odour source was noted. Each test involved 60 larvae and was repeated twice.

Either $2 \mathrm{~g}$ of freshly $\mathrm{dug}$ and washed intact ryegrass ('Grasslands Ruanui') root or its equivalent as a chloroform extract on filter paper, were enclosed in each gauze envelope. Where intact root was tested, the blank gauzes contained damp filter paper; in the case of extracts, the blanks contained filter papers treated with pure solvent.

\section{(2) Gustatory Response}

A wide range of nutrient chemicals were incorporated at various concentrations in a $4 \%$ agar/cellulose powder medium (see Sutherland, 1971 , for details). Test discs $1.5 \mathrm{~cm}$ in diameter were cut from the medium containing each chemical, and similar control discs were cut from medium prepared with distilled water only. One disc was placed in the centre of an empty $5.5 \mathrm{~cm}$ diameter petri dish together with a third instar larva and the lid replaced. After $24 \mathrm{~h}$ the dishes were opened and the number of faecal pellets produced counted. Twenty larvae were exposed to each of the test chemicals.

\section{RESULTS}

\section{Olfactory Stimulants}

A strong olfactory response of $C$. zealandica larvae to the odour of fresh perennial ryegrass root is evident from the results presented in Table 1. Larvae were rapidly attracted to the gauze containing the intact root and within $0.5 \mathrm{~h} 25 \%$ of the larvae had reached the odour source. This proportion increased consistently throughout the course of the experiment.

A close study of the paths followed by individual larvae has shown that almost all those that arrived at the gauze containing the root did so as a result of orientated movement directed towards it-i.e., the larvae moved down an odour gradient to the odour source. Although grubs were unable to come into physical contact with the grass root, all but a very few stayed pressed up against the gauze containing that root until the conclusion of the test. This may indicate the existence of an "arrestant". 
TABLE 1: THE OLFACTORY RESPONSES OF 3rd INSTAR COSTELYTRA ZEALANDICA LARVAE TO GRASS ROOT ODOURS $N=$ number of larvae tested

\begin{tabular}{|c|c|c|c|c|c|}
\hline \multirow[b]{2}{*}{ Odour Source } & \multirow[b]{2}{*}{$N$} & \multirow{2}{*}{$\begin{array}{c}\text { Time } \\
\text { elapsed } \\
(h)\end{array}$} & \multicolumn{2}{|c|}{$\begin{array}{c}\text { No. of Larvae } \\
\text { at Gauze }\end{array}$} & \multirow[b]{2}{*}{ Significance $\dagger$} \\
\hline & & & Blank & Test & \\
\hline Fresh ryegrass root & 120 & $\begin{array}{l}0.5 \\
1.0 \\
2.5\end{array}$ & $\begin{array}{l}9 \\
8 \\
8\end{array}$ & $\begin{array}{l}31 \\
59 \\
93\end{array}$ & $\begin{array}{l}* * * \\
* * * \\
* * *\end{array}$ \\
\hline Chloroform root extract & 114 & $\begin{array}{l}0.5 \\
1.0 \\
2.5\end{array}$ & $\begin{array}{l}14 \\
21 \\
21\end{array}$ & $\begin{array}{l}22 \\
51 \\
55\end{array}$ & $\begin{array}{l}\text { N.S. } \\
* * * * \\
* * *\end{array}$ \\
\hline Extracted root & 114 & $\begin{array}{l}0.5 \\
1.0 \\
2.5\end{array}$ & $\begin{array}{l}10 \\
23 \\
28\end{array}$ & $\begin{array}{l}10 \\
23 \\
49\end{array}$ & $\begin{array}{l}\text { N.S. } \\
\text { N.S. } \\
*\end{array}$ \\
\hline Control (empty $v$. empty) & 120 & $\begin{array}{l}0.5 \\
1.0 \\
2.5\end{array}$ & $\begin{array}{l}18 \\
26 \\
34\end{array}$ & $\begin{array}{l}22 \\
34 \\
30\end{array}$ & $\begin{array}{l}\text { N.S. } \\
\text { N.S. } \\
\text { N.S. }\end{array}$ \\
\hline
\end{tabular}

$\dagger$ Probabilities calculated from binomial distribution.

* Significant at $5 \%$ level.

*** Significant at $0.1 \%$ level.

N.S. Not significant.

While the behavioural response of $3 \mathrm{rd}$ instar larvae to volatile components present in the chloroform extract of ryegrass root was not as strong as was that to intact root, the result of this test (Table 1) presents clear evidence of attraction. The extracted root remains were only very slightly attractive, indicating that those compounds responsible for the larval response had been largely if not entirely removed by treatment with the solvent.

\section{Gustatory STimulants}

A wide range of nutrient chemicals were tested for phagostimulatory activity (Table 2). Of the numerous carbohydrates that induced a feeding response, sucrose had a particularly marked effect on larval feeding and is clearly a strong phagostimulant for this species. Further tests showed that the threshold concentration for a significant larval response to sucrose was $0.001 \mathrm{M}$, while an optimum response occurred at a concentration of $0.1 \mathrm{M}$.

Whereas most of the amino acids tested had no influence on larval feeding, serine, aspartic acid and glutamic acid emerged as quite strong phagostimulants. Alanine, threonine and glutamine also induced a significant response. Ascorbic acid provoked surprisingly intense feeding, perhaps because of the structural similarity between this vitamin and some of those carbohydrates tested.

In accord with the known polyphagy of this insect, it will be seen that those compounds showing activity as feeding stimulants are all widely present in the plant kingdom. Further, analysis of ryegrass root has shown that of the carbohydrates present sucrose comprises approximately $50 \%$, while aspartic and glutamic acids are major components of the amino acid complement (R. W. Bailey, pers. comm.; G. W. Butler, pers. comm.). 


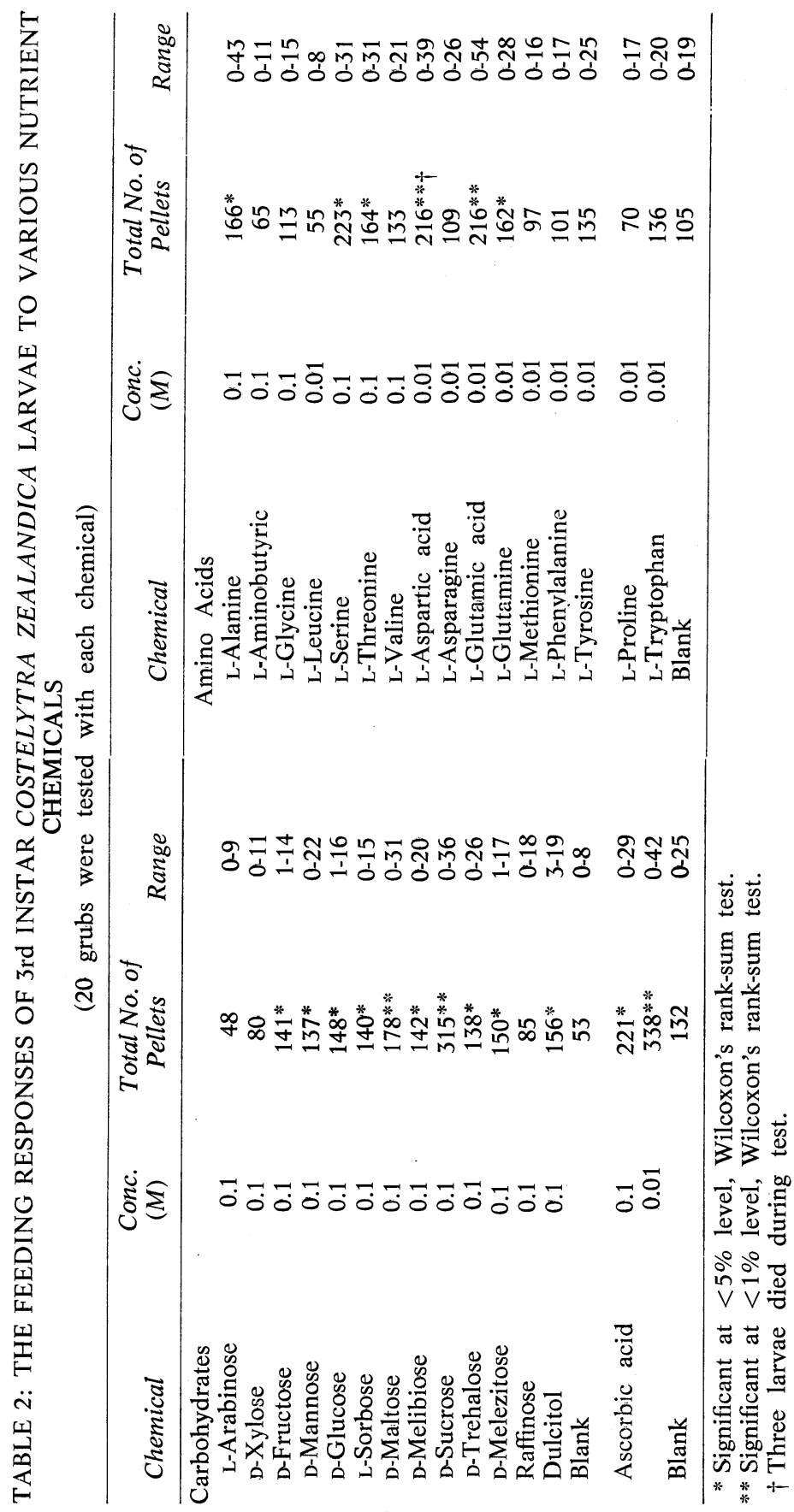

251 


\section{DISCUSSION}

The question of whether or not grass grubs ingest both organic and inorganic matter from soil indiscriminately has never been satisfactorily answered. In a recent study of Sericesthis geminata, Wensler (1971) and Wensler and Dudzinski (1971) obtained clear evidence that larvae of that species selectively ingest organic matter and, indeed, discriminate between various species of food plant. While the present work does not exclude the possibility that $C$. zealandica larvae may ingest some soil particles when they feed, it shows clearly that their feeding behaviour is quite as sophisticated as is that of other phytophagous insects, and that continued feeding is dependent upon the reception of the appropriate chemical cues.

In order to demonstrate the existence of an attractant it is necessary to show orientated movement towards the source of that attractant. The present study has revealed that volatile, chloroform-soluble substances emanating from grass root can indeed draw $C$. zealandica to their food from at least short distances. The isolation and identification of these attractants presents a considerable task, but efforts are under way to achieve this.

Once these compounds are known, it may be possible to breed plants which are not attractive to these pests. It may also be possible to incorporate highly attractive plants as a minor component of a pasture and attract the grubs to them, away from the major pasture component. On the other hand, if the attractant should prove to be easily synthesized, the possibility of using it in quantity to disrupt normal feeding behaviour can be considered.

\section{ACKNOWLEDGEMENTS}

The technical assistance provided by J. Hillier is gratefully acknowledged.

\section{REFERENCES}

Dethier, V. G., 1970. Some general considerations of insects' responses to the chemicals in food plants. In Wood, D. L., Silverstein, R. M., and Nakajima, M. (ed.) : Control of Insect Behaviour by Natural Products. Academic Press, N.Y.

Dethier, V. G.; Barton Browne, L. B.; Smith, C. N., 1960. The designation of chemicals in terms of responses they elicit from insects. J. econ. Ent., 53: 134.

Painter, R. H., 1951. Insect Resistance in Crop Plants. Macmillan, N.Y. Schoonhoven, L. M., 1968. Chemosensory bases of host plant selection. A. Rev. Ent., 13: 115

Sutherland, O. R. W., 1971. Feeding behaviour of the grass grub Costelytra zealandica (White) (Coleoptera : Melolonthinae)-I. The influence of carbohydrates. N.Z. Jl Sci., 14: 18.

1972. Olfactory responses of Costelytra zealandica (Coleoptera: Melolonthinae) larvae to grass root odours. N.Z Jl Sci.: in press.

Wensler, R. J., 1971. Locomotor and feeding activity of larvae of the scarabaeid Sericesthis geminata (Coleoptera). Entomologia exp. appl., 14: 270.

Wensler, R. J.; Dudzinski, A. E., 1971. Gustatory discrimination between plants by larvae of the scarabaeid Sericethsis geminata (Coleoptera). Entomologia exp. appl., 14: 441. 